\title{
Eating Disorders and Menarche: Can Emotions toward the First Period Provide Insight into Future Eating Disorder Development?
}

\author{
Tara Beck ${ }^{*}$, Alison Mancuso ${ }^{2}$, Joanna Petrides ${ }^{2}$ \\ ${ }^{1}$ Rowan University School of Osteopathic Medicine, Stratford, NJ, USA \\ ${ }^{2}$ Department of Family Medicine, Stratford, NJ, USA \\ Email: ^beckt2@rowan.edu
}

How to cite this paper: Beck, T., Mancuso, A., \& Petrides, J. (2017). Eating Disorders and Menarche: Can Emotions toward the First Period Provide Insight into Future Eating Disorder Development? Psychology, $8,1718-1727$.

https://doi.org/10.4236/psych.2017.811113

Received: July 3, 2017

Accepted: September 5, 2017

Published: September 8, 2017

Copyright $\odot 2017$ by authors and Scientific Research Publishing Inc. This work is licensed under the Creative Commons Attribution International License (CC BY 4.0).

http://creativecommons.org/licenses/by/4.0/ (c) (i) Open Access

\begin{abstract}
Objective: There is much ambiguity regarding Eating Disorder (ED) diagnosis, including when a patient actually develops the disease. Many studies have focused on behaviors during late adolescence as a crucial time for ED development, but few have focused on menarche. This study seeks to identify possible behavioral traits during menarche, including emotion toward the first period, which can be used as a warning sign for future ED development. Method: An anonymous online survey was distributed to approximately 1000 female students and faculty at Rowan University School of Osteopathic Medicine and 100 females on an ED Recovery Facebook group. The survey was created and responses were recorded using Rowan Qualtrics system in order to protect patient responses and ensure anonymity. Data was analyzed using SPSS. Results: There were many significant differences found in this study; feelings of fear $(p=0.009)$, sadness $(p=0.021)$ and disgust $(p=0.026)$ toward menarche were significantly higher in those who have been diagnosed with an ED. Additionally, ED patients felt significantly less prepared $(p=0.015)$ for the body changes that occurred during puberty. Those with an ED also experienced significantly increased focus on weight both prior to and during menarche, and reported an increased incidence of self-criticizing their weight to others $(p<0.001)$. Conclusion: The results of this study give insight into behavioral attributes, fear, sadness and disgust, toward a concrete event (menarche) which parents, pediatricians and even school teachers can use to detect early signs of ED behaviors. This provides insight into the development of future diagnostic criteria that caretakers can use to establish early intervention with young, at-risk females to prevent a future ED.
\end{abstract}

\section{Keywords}

Eating Disorder, Menarche 


\section{Background}

Anorexia Nervosa has the highest mortality rate of any psychiatric disorder (Bakalar et al., 2015: p. 1). Eating disorders can be classified based on an array of symptoms, from food restriction and over-exercising to binging and purging, which typically appear 6 - 12 months before a patient is clinically diagnosed (Lock \& La Via, 2015). Regardless of the exact manifestation of symptoms, it is clear that once an Eating Disorder (ED) patient begins showing clinical signs and symptoms, the disease is already deeply rooted in the mind of its victim, causing a sense of denial and disturbed self-concept and body image. While no single factor has been shown to cause EDs, several studies have identified personality traits in children years before diagnosis, which correlate with ED development. Such characteristics include anxiety and depression, perfectionism, obsessiveness, people-pleasing behaviors, and a desire for thinness (Bloks et al., 2004). Although these personality traits are common among ED patients, their expression is not specific enough to warrant concern for an ED in a younger patient.

Current research suggests that patients at risk for developing an eating disorder lack the flexibility of their healthier peers while dealing with novel situations, such as developmental milestones (Bakalar et al., 2015). Although many characteristics have been identified, no study has attempted to link these behavioral traits toward a specific developmental milestone as a correlate for future ED development. Additionally, many studies have highlighted adolescence as a crucial time for the seeds of an ED to take root, however, there has been no correlation between the emotional experience of menarche to the future development of an ED (Klump et al., 2013). This study attempts to determine whether at risk emotions, including fear, sadness, shame, denial, and negative self-image, that a female feels toward her first menstrual period can be indicative of future development of an ED.

Other behaviors that reflect negative body image, including body checking (i.e. when one looks at herself from all angles in the mirror) have been associated with EDs. One study assessing body image at the time of menarche determined that concerns over body image occur as a result of the rapid change in body weight (Abraham \& O'Dea, 2001). As young women become increasingly aware of changes in body weight and shape after their first menstrual period, the behaviors associated with trying to lose weight increase (Haase et al., 2011). In addition to changes in body shape, hormonal changes during menarche may be a precipitant for the onset of disordered eating (Kelly \& Klump, 2003). Given these changes, it seems that early Eating Disorder behaviors may be identifiable around the time of the first period.

Perhaps one of the biggest contributing factors to the development of ED includes the difficulty with diagnosing the disease. One study conducted by Dr. Devdutta Sangvai, Eating Disorders in the Primary Care Setting, highlights many red flags that physicians should be aware of when determining whether a patient has an Eating Disorder. As Dr. Devdutta Sangvai states best, "Patients 
rarely present to the PCP with a chief complaint of 'eating disorder."' More commonly, patients present with other signs and symptoms that are the result of an ongoing eating disorder, including fatigue, weight loss, cold intolerance and menstrual irregularity. However, by the time a physician correctly identifies these symptoms as part of an Eating Disorder, the disease is already engrained in the patient's mind (Sangvai, 2016). These barriers in diagnosis emphasize the importance of early detection and intervention, particularly by the physician. This study will explore behaviors and feelings during menarche that can provide further insight into those at risk for developing an ED.

\section{Methods}

\subsection{Subjects}

This study was conducted through Rowan School of Osteopathic Medicine's Summer Medical Research Fellowship. Given this affiliation with Rowan University, the subjects included approximately 1000 female students and faculty members of Rowan University School of Osteopathic Medicine (Rowan SOM) and approximately 100 female members of a Facebook Eating Disorder Support Group. The inclusion criteria was females 18 years and older. The study was approved by Rowan SOM's Institutional Review Board. A consent statement was displayed at the beginning of the survey and completion of the survey implied consent.

\subsection{Instrument}

An anonymous, 19-question online survey was created using Rowan Qualtrics. A link to the survey was distributed via email to the students of Rowan SOM and posted on a Facebook Eating Disorder Support Group. Data was securely stored within the Qualtrics account; only study investigators were able to access the data.

\subsection{Procedure}

The survey was administered from June 14, 2016 through July 4, 2016. There were a total of 288 responses collected. Survey questions included age of first period and the presence of a clinical diagnosis of an Eating Disorder. The survey also included questions about emotions related to menarche (i.e.: anger, happiness, fear, sadness, disgust, surprise toward first period, and feelings of shame toward the first period) which were asked using a 5-point Likert Scale. Participants were asked to rate their feelings from a range of "Clearly Describes My Feelings" to "Does Not Describe My Feelings". Other questions focused on weight and body image, including determining body image during puberty and around the time of menarche; the focus of weight during puberty; body checking behaviors around the time of first period; and self-criticism of one's body during the time of the first period. 


\subsection{Analysis}

For the purpose of analysis, subjects were divided based on the presence of a clinical diagnosis of an ED. There were 65 females (23\% of participants)who met the "ED Yes" criteria, meaning they have received a clinical ED diagnosis. The remaining 223 females indicated they were not clinically diagnosed with an Eating Disorder therefore they were categorized as "ED No." One patient from the "ED No" group was excluded due to not meeting the age criterion, so her data was not included in the statistical analysis. The data was analyzed using SPSS in order to determine significant statistical differences in survey responses between the "ED Yes" and "ED No" participants.

\section{Results}

\subsection{Subjects}

The average age for participation for the "ED No" group was 24.96 (SD \pm 6.2 ) years while "ED Yes" group's mean age was $26.18(\mathrm{SD} \pm 7.62)$ years. The mean age of menarche for the "ED No" participants was 12.44 (SD \pm 1.48 ) years while the "ED Yes" participants mean age of menarche was $12.78(\mathrm{SD} \pm 1.90)$ years.

\subsection{Emotions toward Menarche}

When asked to rate the feelings toward menarche using a 5-quality Likert Scale, ranging from "Clearly Describes My Feelings" to "Does Not Describe My Feelings," there was a significant difference in the expression of fear toward the first period between the ED Yes and ED No group. The ED Yes members showed a significant amount of fear toward the event $(p=0.009)$, illustrated in Figure 1. Additionally, the ED Yes group significantly reported feelings of sadness ( $p=$ $0.021)$ and disgust $(p=0.026)$ toward menarche, shown in Table 1.

\subsection{Weight and Body Image}

Participants were asked whether they felt prepared for the body changes that

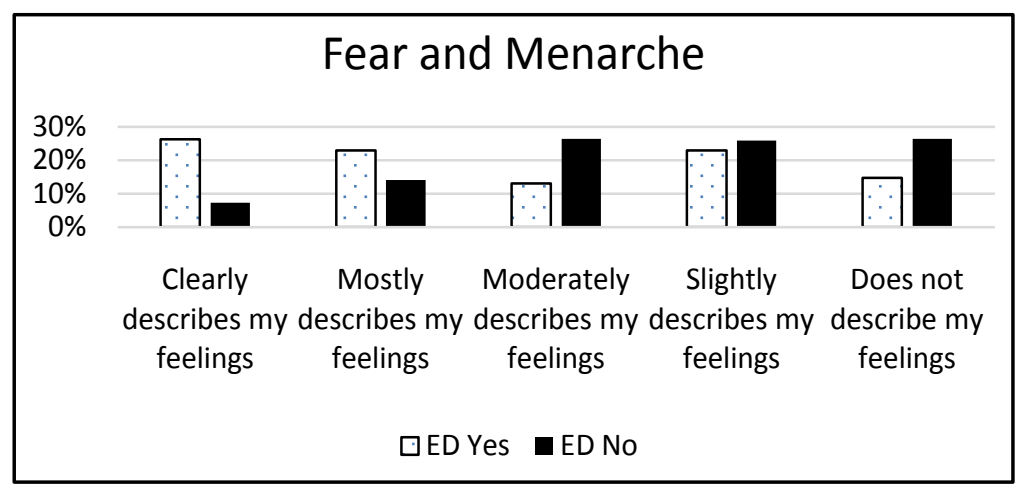

Figure 1. Levels of Fear Toward Menarche: The comparative levels of fear felt toward menarche between those who developed Eating Disorders and those who did not. There is a significant correlation $(p=0.009)$ between those who experienced fear toward their first periods and future ED development. 
Table 1. Levels of Fear, Sadness and Disgust toward menarche and the Propensity for ED Development: Independent samples T-test comparing the degree which the two groups of this study, those who have been clinically diagnosed with an Eating Disorder and those who have not, experienced fear, sadness and disgust toward the first period.

\begin{tabular}{|c|c|c|c|c|c|c|c|c|c|c|}
\hline & & \multicolumn{9}{|c|}{ Independent Samples Test } \\
\hline & & \multicolumn{2}{|c|}{$\begin{array}{c}\text { Levene's Test for } \\
\text { Equality of } \\
\text { Variances }\end{array}$} & \multicolumn{7}{|c|}{ t-test for Equality of Means } \\
\hline & & \multirow[t]{2}{*}{$\mathrm{F}$} & \multirow[t]{2}{*}{ Sig. } & \multirow[t]{2}{*}{$\mathrm{t}$} & \multirow[t]{2}{*}{ df } & \multirow[t]{2}{*}{$\begin{array}{c}\text { Sig. } \\
\text { (2-tailed) }\end{array}$} & \multirow[t]{2}{*}{$\begin{array}{c}\text { Mean } \\
\text { Difference }\end{array}$} & \multirow[t]{2}{*}{$\begin{array}{l}\text { Std. Error } \\
\text { Difference }\end{array}$} & \multicolumn{2}{|c|}{$\begin{array}{l}\text { 95\% Confidence } \\
\text { Interval of the } \\
\text { Difference }\end{array}$} \\
\hline & & & & & & & & & Lower & Upper \\
\hline \multirow{2}{*}{$\begin{array}{c}\text { Fear } \\
\text { toward } \\
\text { menarch }\end{array}$} & $\begin{array}{c}\text { Equal } \\
\text { variances } \\
\text { assumed }\end{array}$ & 6.986 & 0.009 & -4.034 & 278 & 0.000 & -0.741 & 0.184 & -1.103 & -0.379 \\
\hline & $\begin{array}{c}\text { Equal } \\
\text { variances not } \\
\text { assumed }\end{array}$ & & & -3.666 & 85.228 & 0.000 & -0.741 & 0.202 & -1.143 & -0.339 \\
\hline \multirow{2}{*}{$\begin{array}{l}\text { Sadness } \\
\text { toward } \\
\text { menarch }\end{array}$} & $\begin{array}{c}\text { Equal } \\
\text { variances } \\
\text { assumed }\end{array}$ & 5.429 & 0.021 & -2.245 & 280 & 0.026 & -0.411 & 0.183 & -0.770 & -0.051 \\
\hline & $\begin{array}{c}\text { Equal } \\
\text { variances not } \\
\text { assumed }\end{array}$ & & & -2.086 & 87.230 & 0.040 & -0.411 & 0.197 & -0.802 & -0.019 \\
\hline \multirow{2}{*}{$\begin{array}{l}\text { Disgust } \\
\text { toward } \\
\text { menarch }\end{array}$} & $\begin{array}{c}\text { Equal } \\
\text { variances } \\
\text { assumed }\end{array}$ & 5.012 & 0.026 & -4.236 & 282 & 0.000 & -0.728 & 0.172 & -1.066 & -0.390 \\
\hline & $\begin{array}{c}\text { Equal } \\
\text { variances not } \\
\text { assumed }\end{array}$ & & & -3.873 & 89.164 & 0.000 & -0.728 & 0.188 & -1.101 & -0.354 \\
\hline
\end{tabular}

take place during puberty. ED Yes respondents significantly reported that they did not feel prepared for these body changes $(p=0.015)$. These responses are highlighted in Figure 2. Additionally, the survey asked participants whether they focused on weight during menarche; the ED Yes participants reported significant increased focus on their weight $(p<0.001)$ compared to the ED No group. Additionally, when asked, "Prior to receiving your first period, do you remember thinking about your weight?" ED Yes respondents reported more focus ( $p=$ $0.019)$ even prior to puberty, compared with ED No. The survey also inquired events such as body checking, which is a common technique used among ED patients. When asked, "Did you ever body check around the time of your first period (i.e.: look at yourself undressed in the mirror, lift up shirt, etc.)," there was no significant difference in frequency between the two groups. The final component of the survey inquired about self-criticism and asked, "Were you self-critical of your body around the time of your first period?" Both ED Yes and ED No respondents reported feelings of criticism. However, this question was followed up by asking, "Would you ever self-criticize your body to others," to 
which the ED Yes respondents overwhelmingly reported that they would self-criticize their bodies to others much more frequently than ED No participants $(p<0.001)$, highlighted in Figure 3 and Table 2.

\section{Discussion}

The results of this study highlight significant differences in feelings expressed toward menarche between females who went on to develop an ED and those who did not The results show that emotions toward the first period, particularly fear, sadness and disgust, can be predictive toward future ED development. These findings give insight into behavioral attributes toward a concrete event

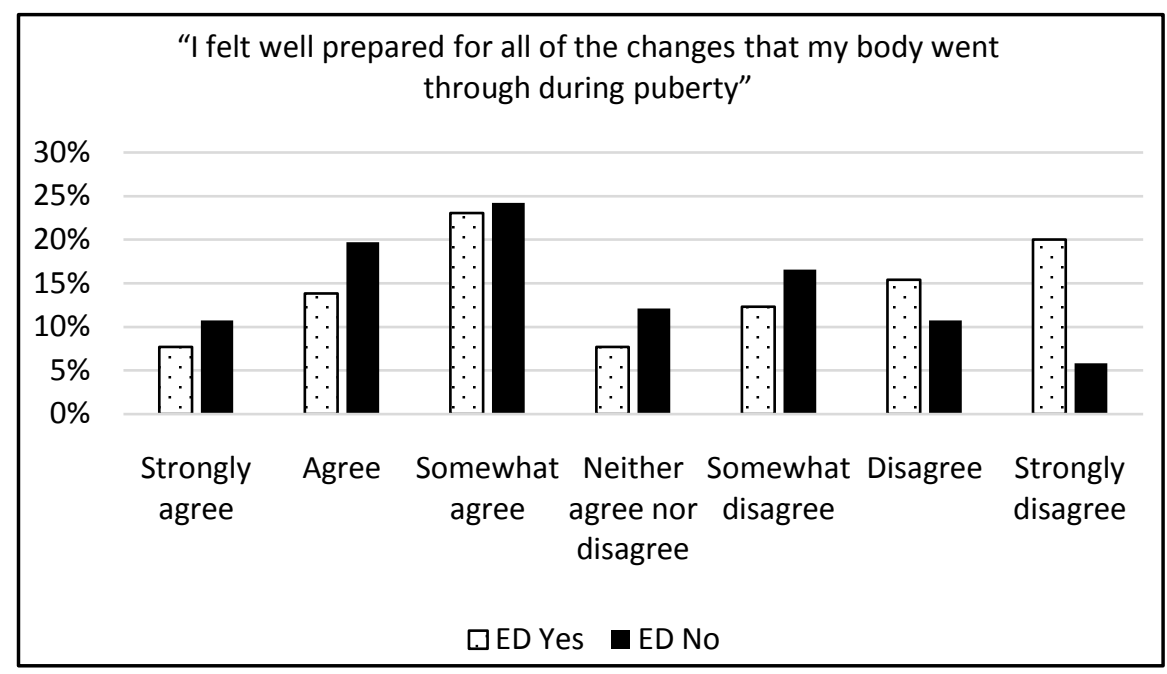

Figure 2. Preparedness for the body changes of puberty: Comparative preparedness for body changes during puberty between the ED Yes and No group showed significant differences $(p=0.015)$. Those diagnosed with an ED felt less prepared for the changes that their body went through during puberty.

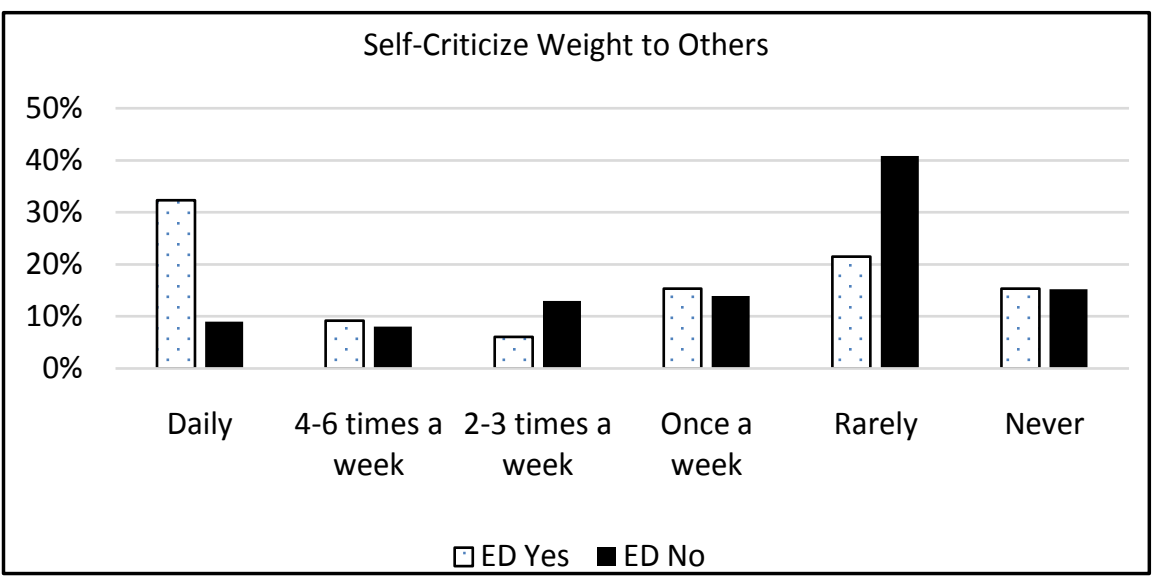

Figure 3. How often women self-criticized their weight to others at the time of menarche: Data measuring how often females would self-criticize their weight to others. Those who have been diagnosed with an eating disorder reported they would self-criticize their weight to others much more frequently than those who have never been diagnosed with an $\operatorname{ED}(p<0.001)$. 
Table 2. Comparing frequency of self criticism of weight to others during menarche: Independent samples T-test showing the statistical significant data in Figure 3 measuring the frequency that those with an ED would self-criticize their weight to others. The data show that the ED Yes group would express their self-criticism of their weight to others much more frequently.

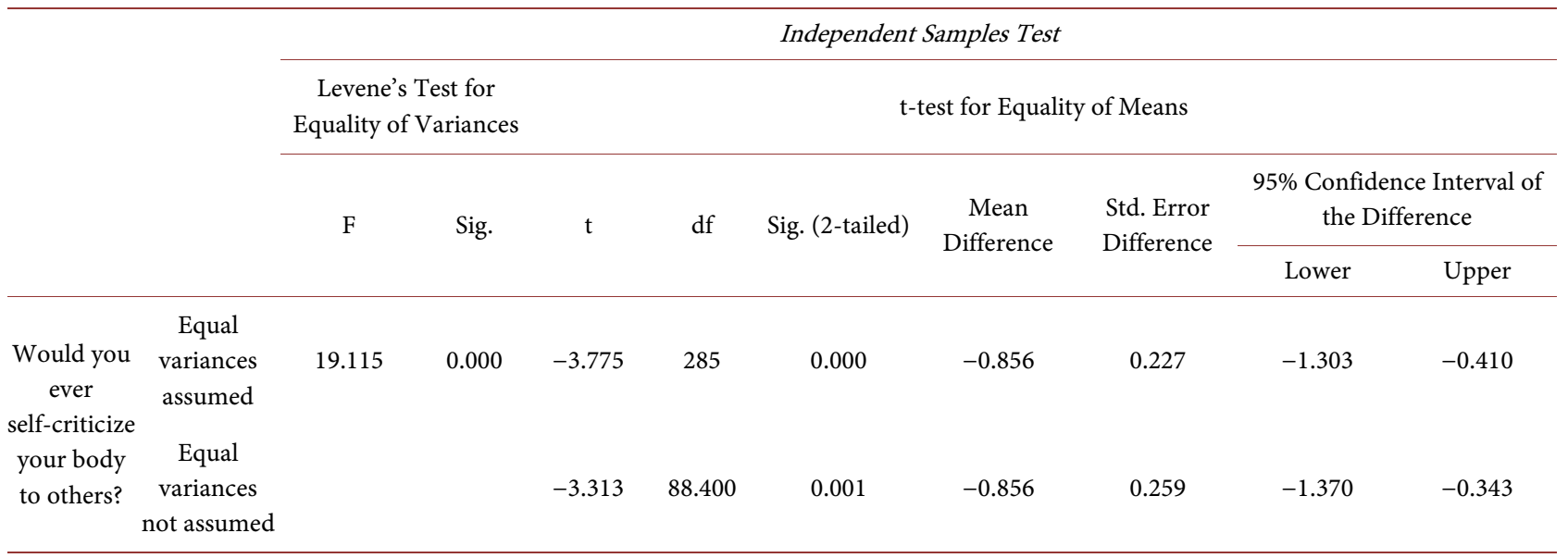

that parents, pediatricians and even school teachers can use to detect early signs of ED behaviors. This sets up a diagnostic criterion that caretakers can use to establish an intervention with young, at-risk females to change their body image and prevent the future clinical diagnosis of an ED.

While prior studies indicate that an educational intervention is necessary in order to improve awareness and reduce the risk of Eating Disorder development, there is debate about identifying an appropriate time to implement such intervention. One study analyzing BMI, Menarche and Perception of Dieting Among Peripubertal Adolescent Females claims that feelings associated with weight loss and dieting did not develop until menarche, a time highlighted by increased height, weight, and body fat accumulation (Boyd et al., 2009). The results of this study support menarche as a crucial time in ED development and provide evidence that the first period could be an appropriate time to intervene when at-risk behaviors, particularly fear, sadness and disgust toward the first period, are seen in young females. Once these feelings are assessed and identified, caretakers can take extra precaution to monitor the female and prevent the future development of an Eating Disorder.

\subsection{Fear and Eating Disorders}

The significant feelings of fear that patients with EDs felt at the time of menarche further supports the idea that EDs and anxiety disorders are often comorbid. It has been suggested that adolescent girls diagnosed with EDs should be concomitantly examined for the presence of mood and anxiety disorders. Similarly, adolescent females diagnosed with anxiety and mood disorders should be examined for the presence of an ED (Touchette et al., 2011). However, it is often difficult to measure and compare females' anxiety levels without a controlled event. This study provides a controlled developmental milestone, menarche, in order to determine the difference in expression of fear and disgust toward the 
first period between females who went on to develop an ED and those who did not. The data shows that fear toward the first period is a strong indication for ED prevalence and should be used as a clinical marker by pediatricians, teachers, and caregivers to prompt further investigation for the presence of an ED. Accordingly, even if an adolescent female does not yet display the clinical signs of an $\mathrm{ED}$, early intervention should be made due to this strong correlation between fear toward menarche and future ED Development.

\subsection{Intervention}

The results of this study provide diagnostic criteria that physicians can use to implement early intervention. Prior studies have found much success in ED prevention through intervention programs. One pilot study conducted in 2015 sought to determine the effectiveness of the Body Project, an eating disorder prevention program, at reducing negative body image among randomized females between the ages of $13-17$. The results showed that the intervention was successful in reducing thin-ideal internalization, dieting and eating disorder symptoms post-intervention, and persisted through a 3-month follow-up appointment (Linville et al., 2015). When applied with the results found in this study, screening for behaviors toward the first period, coupled with early intervention, can perhaps reduce the prevalence of EDs by identifying females who may be at risk for future development.

While parents and guardians can certainly observe these at-risk emotions seen in young girls at the time of the first period, it is important for physicians to inquire about a patient's first period. Many participants in this survey (80.27\%) claimed that their doctor did not even discuss the body changes that occur during puberty. In order to provide comprehensive care to patients, physicians must take the time to discuss the first period and intervene in cases where the female displays at-risk behaviors described in this study. Appropriate conversations, including lessons in well-being, discussions that promote healthful mind and body image, including self-love and how to cope with body changes during puberty, can certainly be addressed and provide a platform for physicians to observe a young girl's reaction to the topic of menarche and identify those at risk for future ED development. Many ED studies show that early identification and intervention increases the likelihood that a female will be receptive to treatment (O’Dea et al., 1999: p. 671).

\subsection{Study Limitations}

While this study inquired about the age of menarche and presence of a clinical Eating Disorder diagnosis, it did not ask the age of diagnosis. Although there is a notion that Eating Disorders are typically a disease diagnosed after puberty, there are many studies that suggest pre-menarcheal girls are at risk for developing Eating Disorders, as well (Becker et al., 2004). This could have skewed the results, particularly if respondents had an Eating Disorder at the time of menarche. 
An additional limitation includes the restriction put on the clinical diagnosis of an Eating Disorder. Many participants could have disordered eating symptoms, but have not been clinically diagnosed with an Eating Disorder by a physician. A way to eliminate this uncertainty in future studies includes implementing a disordered eating questionnaire, such as EDE-Q or EAT-26, to determine whether a participant has disordered eating characteristics that could categorize her as an "ED Yes" patient and analyze the results using that.

\subsection{Future Direction}

Follow-up studies can determine the success of intervention programs, either established by the school or pediatrician. For instance, one future study can assess the efficacy of an intervention based on the presence of ED behaviors in a female at the time of menarche pre and post intervention.

Future research can also determine differences within the Eating Disorder group. Results from a 2005 study inquiring about the attitudinal differences in body image between patients with anorexia nervosa and bulimia nervosa showed that individuals with bulimia reported more body image dissatisfaction than those diagnosed with anorexia (Swenne \& Thurfjell, 2003). Using this concept, a future study can select participants with an Eating Disorder diagnosis and seek to determine different feelings toward menarche between the diagnoses. This information can be useful to apply interventions specifically preventing behaviors of certain EDs (anorexia vs. bulimia vs. unspecified ED).

\section{Institutional Review Board Statement}

Our Institutional Review Board approved this study; informed consent was presented to each participant at the start of the survey and consent was implied by survey participation.

\section{Financial Support}

None. The authors did not receive any outside funding in support of this research or manuscript preparation. They did not receive payment or any benefits from commercial entities.

\section{Conflict of Interest}

The authors do not have any conflicts of interest to disclose.

\section{References}

Abraham, S., \& O’Dea, J. A. (2001). Body Mass Index, Menarche and Perception of Dieting among Peripubertal Adolescent Females. International Journal of Eating Disorders, 29, 23-28. https://doi.org/10.1002/1098-108X(200101)29:1<23::AID-EAT4>3.0.CO;2-Z

Bakalar, J. L., Shank, L. M., Vannucci, A., Raddin, R. M., \& Tanofsky-Kraff, M. (2015). Recent Advances in Developmental and Risk Factor Research on Eating Disorders. Current Psychiatry Reports, 17, 42. 
Becker, A. E., Franko, D. L., Nussbaum, K., \& Herzog, D. B. (2004). Secondary Prevention for Eating Disorders: The Impact of Education, Screening and Referral in a College-Based Screening Program. International Journal of Eating Disorders, 36, 157-162. https://doi.org/10.1002/eat.20023

Bloks, H., Hoek, H. W., Callewaert, I., \& Van Furth, E. (2004). Stability of Personality Traits in Patients Who Received Intensive Treatment for a Severe Eating Disorders. The Journal of Nervous and Mental Disease, 192, 129-138. https://doi.org/10.1097/01.nmd.0000110284.12816.fe

Boyd, C., Abraham, S., Maala, L., Luscombe, G., \& Taylor, A. (2009). Time Since Menarche, Weight Gain and Body Image Awareness among Adolescent Girls: Onset of Eating Disorders? Journal of Psychosomatic Obstetrics \& Gynecology, 30, 89-94. https://doi.org/10.1080/01674820902950553

Haase, A. M., Mountford, V., \& Waller, G. (2011). Associations between Body Checking and Disordered Eating Behaviors in Nonclinical Women. International Journal of Eating Disorders, 44, 465-468. https://doi.org/10.1002/eat.20837

Kelly, L., \& Klump, K. (2013). Puberty as a Critical Risk Period for Eating Disorders: A Review of Human and Animal Studies. Hormones and Behavior, 64, 399-410. https://doi.org/10.1016/j.yhbeh.2013.02.019

Klump, K. L., McGue, M., \& Iacono, W. G. (2003). Different Heritability of Eating Attitudes and Behaviours in Prepubertal versus Pubertal Twins. International Journal of Eating Disorders, 33, 287-292. https://doi.org/10.1002/eat.10151

Linville, D., Cobb, E., Lenee-Bluhm, T., López-Zerón, G., Gau, J. M., \& Stice, E. (2015). Effectiveness of an Eating Disorder Preventative Intervention in Primary Care Medical Settings. Behaviour Research and Therapy, 75, 32-39. https://doi.org/10.1016/j.brat.2015.10.004

Lock, J., \& La Via, M. C. (2015). Practice Parameter for the Assessment and Treatment of Children and Adolescents with Eating Disorders. Journal of the American Academy of Child and Adolescent Psychiatry, 54, 412-425.

https://doi.org/10.1016/j.jaac.2015.01.018

O’Dea, J. A., \& Abraham, S. (1999). Onset of Disordered Eating Attitudes and Behaviours in Early Adolescence: Interplay of Pubertal Status, Gender, Weight and Age. Adolescence, 34, 671-679.

Sangvai, D. (2016). Eating Disorders in the Primary Care Setting. Primary Care: Clinics in Office Practice, 43, 301-312. https://doi.org/10.1016/j.pop.2016.01.007

Swenne, I., \& Thurfjell, B. (2003). Clinical Onset and Diagnosis of Eating Disorders in Premenarcheal Girls Is Preceded by Inadequate Weight Gain and Growth Retardation. Acta Paediatrica, 92, 1133-1137. https://doi.org/10.1111/j.1651-2227.2003.tb02472.x

Touchette, E., Henegar, A., Godart, N., Pryor, L., Fallissard, B., Tremblay, R., \& Cote, S. (2011). Subclinical Eating Disorders and Their Comorbidity with Mood and Anxiety Disorders in Adolescent Girls. Psychiatry Research, 185, 185-192.

https://doi.org/10.1016/j.psychres.2010.04.005 
Submit or recommend next manuscript to SCIRP and we will provide best service for you:

Accepting pre-submission inquiries through Email, Facebook, LinkedIn, Twitter, etc. A wide selection of journals (inclusive of 9 subjects, more than 200 journals)

Providing 24-hour high-quality service

User-friendly online submission system

Fair and swift peer-review system

Efficient typesetting and proofreading procedure

Display of the result of downloads and visits, as well as the number of cited articles Maximum dissemination of your research work

Submit your manuscript at: http://papersubmission.scirp.org/

Or contact psych@scirp.org 